\title{
Developing an Industry Job Simulation Program for Graduate and Postdoctoral Trainees in Life Sciences
}

\author{
Katelyn Kozma \\ University of Toronto, The Hospital for Sick Children \\ Anne Meyer-Miner \\ University of Toronto, The Hospital for Sick Children \\ Jonathan Chio \\ University of Toronto, University Health Network \\ Stefanie Mak \\ University of British Columbia \\ Ahmed El-Boraie \\ University of Toronto, Centre for Addition and Mental Health \\ David Sealey \\ University of Toronto, Science Career Impact Project
}

\begin{abstract}
In the life sciences, many graduate students and postdoctoral fellows find it challenging to enter the non-academic workforce after completing their programs. Through experiential learning, trainees can develop the knowledge, technical skills, soft skills, and project portfolio that employers value, and compete effectively in the job market. In this article, we share design considerations for developing a job simulation program based on our experience over 5 years with the Industry Team Case Study program at the University of Toronto. In this program, which is focused on the biopharmaceutical sector, trainees identify a business or policy challenge, conduct in-depth research, develop a solution to address the problem, and present their findings to industry professionals. For mentorship and coaching, trainees are matched with industry professionals. This article covers four areas of program development: starting the program, recruiting advisors and trainees, designing the program and project framework, and evaluating program effectiveness. Academic institutions and student organizations can use this information to start their own job simulation programs focused
\end{abstract}

on their employment sector of interest. Employers can participate in these programs to develop and scout talent.

Across North America a minority of life and health sciences $\mathrm{PhD}$ graduates become tenured faculty (Council of Canadian Acadmies, 2021; Edge \& Munro, 2015; Langin, 2019). Moreover, a substantial proportion gain employment in a non-academic sector. For example, in 2016 over $40 \%$ of University of Toronto life science $\mathrm{PhD}$ graduates from 2000 to 2015 were employed in a non-academic sector (Reithmeier et al., 2019). Similar findings were reported at the University of British Columbia for the 2005 to 2013 period (Porter et al., 2017). Studies have reported that the interest of life science $\mathrm{PhD}$ candidates in non-academic careers trends higher towards the completion of training (Fuhrmann et al., 2011; Her et al., 2018; Roach \& Sauermann, 2017) Despite the interest of trainees (graduate students and postdoctoral fellows) in non-academic careers, many find it challenging to enter the workforce after graduation (Council of Canadian Acadmies, 2021; Edge \& Munro, 2015).

Life science trainees may encounter 'skills gaps' when pursuing industry careers. Even though they have advanced knowledge and skills, trainees may be unaware of career paths available to them or how to connect the soft skills they have with those sought out by employers (Archer-Kuhn \& Rancourt, 2019; Council of Canadian Acadmies, 2021; Craig \& Markowitz, 2017; Edge \& Munro, 2015; Tomasson Goodwin et al., 2019). In addition, some trainees may need more opportunities to develop the soft skills sought out by employers (BioTalentCanada, 2020; Council of Canadian Acadmies, 2021; Edge \& Munro, 2015).

In either case, experiential learning programs can help trainees prepare themselves for the job market. Such opportunities include internships (temporary employment at a trainee level), job simulation (completing projects like those done by professionals but in a non-employment context), job shadowing (observing a professional in the workplace to learn about job expectations), and site visits (observational visits to a workplace) (Council of Canadian Acadmies, 2021; Edge \& Munro, 2015; Wart et al., 2020). Experiential learning activities are associated with benefits for trainees including recognition of transferable skills (Sealey et al., 2020; Sinche et al., 2017; Yung 
et al., 2019), confidence in choosing a career path (Schnoes et al., 2018; Sealey et al., 2020; Yung et al., 2019), facilitating the transition to employment (BioTalent Canada, 2020; Edge \& Munro, 2015; Her et al., 2018; Sealey et al., 2020; Yung et al., 2019) and decreased likelihood of pursuing postdoctoral positions as a default (Schnoes et al., 2018), while having little to no negative impact on time to degree completion (Brandt et al., 2020; Lenzi et al., 2020; Schnoes et al., 2018) or research productivity as measured by publications (Brandt et al., 2020). Benefits for employers include a stronger talent pool (i.e., applicants who have sector knowledge, technical skills, and interpersonal skills).

Despite the benefits of experiential learning, many life science graduate departments continue to focus on training students for academic careers (Fuhrmann et al., 2011). While there have been efforts to meet the demand in the United States and Canada (Council of Canadian Acadmies, 2021; Edge \& Munro, 2015; Lenzi et al., 2020; Meyers et al., 2016; Mitacs, 2020; School of Graduate Studies, 2020; University of Alberta, 2020) experiential learning opportunities are uncommon.

To address this unmet need, the Industry Team Case Study (ITCS) job simulation program was established within the University of Toronto community by the Science Career Impact Project (volunteer organization in Toronto) and the Life Sciences Career Development Society (student-run professional development organization at the University of Toronto). Since 2016, more than 180 life science Master's, $\mathrm{PhD}$, and postdoctoral trainees have participated, many of whom have leveraged their experience to chart their career path and gain employment (Sealey et al., 2020; Yung, et. al., 2019). In this four-month, extra-curricular, voluntary program focused on the biopharmaceutical sector, trainees work in teams to identify a business or policy challenge, conduct in-depth research and analysis, develop a strategy or solution to address the problem, and present their findings to industry professionals. For mentorship and coaching, trainee teams are matched with industry professionals. By providing trainees with a platform to develop a portfolio of simulated project experience, the ITCS program aims to streamline the path to employment. ITCS alumni cite that the program helped them build specialized knowledge, professional networks, and relevant industry experience which allowed them to market themselves effectively during job interviews (Sealey et al., 2020; Yung et al., 2019).

In this article, we share design considerations for developing a job simulation program based on our experience with the ITCS program. We cover four aspects of program development: (1) Starting the program; (2) Recruiting advisors and trainees; (3) Designing the program and project framework; and (4) Evaluating program effectiveness. Our hope is that academic institutions and student organizations will leverage this material to start their own job simulation programs focused on their employment sector of interest.

\section{Starting the Program}

\section{Identify the Need and Set the Scope}

The impetus to start a job simulation program can come from trainees, academic institutions, and/or employers. Trainees may wish to boost their employment prospects, departments or institutions may recognize an opportunity to better prepare their trainees for the workforce, and employers may seek more capable new hires. To assess demand for a job simulation program, surveying trainees, alumni and employers, and tracking alumni can identify employment trends and unmet career development needs (BioTalent Canada, 2020; Her et al., 2018; Silva et al., 2019).

A job simulation program can target any sector. After identifying the sector, consider the specific disciplines in which professionals are employed. To appeal to life science trainees, the ITCS program focuses on the biopharmaceutical sector and has covered medical affairs, regulatory affairs and policy, health technology assessment/market access, method development, product development, business development, and marketing/ commercialization.

\section{Establish an Organizing Committee of Trainees and Professionals}

To address the talent development needs of both trainees and employers (Hitchcock et al., 2017), we recommend establishing an organizing committee including an executive team of trainees who represent potential participants, and an advisory board of industry professionals (Table 1). Academic administrators and faculty can also participate. The organizing committee will articulate a mission for the program, prepare a budget and secure funding, design the program structure and schedule, recruit trainees and advisors, and run the program (Table 2).

To staff the executive team, trainees can be recruited through academic departments/units, student organizations, and professional development societies. Ideally, the team will reflect the academic breadth 
of the target trainee participants.

Including junior and senior students and postdoctoral fellows will help to balance the level of experience with developing future leaders for the program.

To form the advisory board, industry professionals can be recruited from alumni and community networks. As more trainees pursue industry careers, more industry professionals understand the need to mentor trainees and support programs that aid in that transition (BioTalent Canada, 2020).

The ITCS program organizing committee has included an executive team of three to five trainees, and an advisory board of one to three professionals from the biopharmaceutical industry who serve as volunteers.

\section{Secure a Program Sponsor}

A sponsor that supports the mission of the program can provide funding and resources (eg, venue space), raise awareness of the program, and champion its success (Table 1). Suitable sponsors may include academic divisions or departments, faculty members, professional societies, employers, or industry organizations. Academic institutions aiming to increase the value of their programming and their connections with employers will benefit from participating. Institutions with strong alumni employment metrics are likely to attract top students (Craig \& Markowitz, 2017). Employers and industry organizations may see an opportunity to build a focused talent pipeline and scout highly skilled candidates (BioTalent Canada, 2020). Donations and grants may also provide funding.

The ITCS program has been sponsored and funded by Graduate and Life Sciences Education at the Faculty of Medicine, University of Toronto (University of Toronto, 2020). The program has also been funded by Community-Engaged Initiatives Grants from the Center for Community Partnerships, University of Toronto (Division of Student Life, 2020).
Recruiting Advisors and Trainees

Recruit Industry Professionals who are Committed to Talent

Development

As advisors, industry professionals coach and mentor trainees who have specialized knowledge but have not worked in the target discipline. Advisors provide guidance and feedback on the scope and relevance of trainees' projects, appropriateness of information sources, and the quali-

Table 1

Job Simulation Program Stakeholders and Roles

Sponsor Academic division, department or faculty / Professional society / Employer / Industry organization

- Support program mission

- Provide funding and resources

- Raise awareness of the program and champion its success

Organizing Executive team (Graduate students and postdoctoral fellows) and Committee Industry advisory board

- Articulate program mission

- Prepare budget and secure funding

- Design program structure and schedule

- Recruit trainees and advisors

- Run the program

\begin{tabular}{lll}
\hline Program & Trainees & Advisors \\
Participants & Graduate students & Industry professionals
\end{tabular}

Postdoctoral fellows

- Identify a business or policy challenge

- Conduct research and analysis

- Propose a strategy or solution to address the problem

- Provide guidance and feedback on project scope and relevance, appropriateness of information sources, and quality of deliverables

- Explain complex aspects of their field

- Present findings 
ty of deliverables (Table 1). Advisors also explain complex aspects of their field.

It is important to select advisors who are motivated by the goodwill of helping early-stage professionals start their careers, in alignment with the program mission and framework. Advisors may also seek to gain talent development experience that can be leveraged to advance their own careers. Setting clear expectations of the time commitment and roles and responsibilities during on-boarding can help advisors stay engaged. During the program, the organizing committee should check in with advisors regularly to address their questions or concerns as they arise.

We recommend recruiting advisors at least four months in advance of the program start date to allow coordination of schedules. Potential advisors can be identified through alumni and professional networks. Trainee alumni of the program who are working in industry may wish to return as advisors, and can also recruit colleagues by sharing how the program benefited them.

The ITCS program has started to become self-sustaining with several advisors participating over multiple years and trainee alumni returning as advisors.

\section{Recruit Trainees who are Motivated to Develop Their Professional Skills}

Many trainee candidates will have defined their development objectives and target career path, while others may have only started to reflect on their strengths and explore what to do after graduation. We recommend hosting a pre-program information session to introduce the advisors and disciplines, convey the benefits and structure of the program, and help trainees focus their objectives (Table 2). After adding an information session to the ITCS program, trainees were better informed and were more likely to apply to and complete the program.

Recruitment advertising can be directed through department e-mail listservs and social media (e.g, LinkedIn, Twitter). Enlisting the support of graduate student unions and professional societies can also raise awareness.

Applications to the ITCS program have included a one-page resume and a brief project proposal. Short answer questions require applicants to communicate basic knowledge in the field, and overall readiness to undertake a project. In the ITCS program participants apply as individuals. Alternatively, participants can apply in teams.

In the ITCS program, trainees are expected to take ownership of their projects. Selecting applicants who clearly articulate their professional development goals and provide evidence of their readiness to participate will improve the experience for all participants. To identify strong candidates, the organizing committee looks for evidence of teamwork and leadership skills. The organizing committee sets a minimum standard, scores applications and selects topranked trainees based on program capacity (discussed below). In recent years, the ITCS program acceptance rate has been approximately $60 \%$.

The organizing committee assigns trainee teams. We recommend balancing trainees' stage of degree completion (early year, senior year, postdoctoral fellow), area of research, leadership strengths, and level of industry knowledge, while considering equity, diversity and inclusion principles.

\section{Designing the Program and Project Framework}

\section{Define the Program Framework, Duration and Scale}

Trainees can work on projects in teams or independently. A teambased approach will allow trainees to develop their collaboration skills and distribute tasks. On the other hand, working independently will involve autonomy, while requiring more effort to investigate various aspects of a project.

Trainee teams (or individuals) can be matched with a single advisor or panel of advisors (Figure 1). A single advisor will deliver more cohesive and consistent feedback throughout the program. Alternatively, a panel of advisors will offer different perspectives based on a wider range of experience. The advisor experience should also be considered: whether to engage with teams independently or with a panel of peers. An adequate ratio of advisors to teams is needed to provide trainees with enough contact time and feedback.

The program should be long and immersive enough for trainees to develop knowledge and skills in the discipline, and complete a robust project while respecting that participants may have other obligations. If the program is not a core component of a curriculum or employer initiative, participants will be participating during their personal time.

The scale of the program will be limited by the number of advisors and the size of venues if hosting events in-person. In the pilot year, the ITCS program enrolled three trainee teams of three to five members each. Each team was paired with one advisor. The program then expanded to 10 to 12 teams, each team paired with one advisor, or, in a recent iteration, 
a panel of three advisors (Figure 1). The program duration is four months, similar to the length of an academic semester (Table 2). Trainees have found this duration to be acceptable, and advisors - who meet periodically with trainees - have commented that it is manageable and typical of projects in their field.

\section{Projects Should Introduce Trainees to the Challenges, Deliverables, and Tools of Their Target Discipline}

By working on a simulated project ('case study') relevant to their chosen field, trainees will gain valuable knowledge and insights, and expand their portfolio. Project concepts can be informed by current trends and topics of interest, and can be defined by trainees or advisors. While trainees may find it challenging to define a project, working through this challenge can be empowering and lead to higher engagement. In general, ITCS advisors have provided positive feedback on the trainee-driven approach, and supported trainees in taking time to investigate the field and create unique projects.

Alternatively, having advisors play a more active role in conceptual- izing a relevant project, and for which they are well-suited to providing feedback, can be more efficient. To avoid real or perceived conflicts of interest, we recommend that advisors not select a topic that overlaps with their projects at work. The organizing committee can also share examples of project themes and past projects (Table 3).

\section{Facilitate Meaningful Interactions Between Trainees and Advisors}

As trainees discuss progress and challenges, they will learn a lot from their advisors who provide guidance and feedback. We encourage trainees to consider this feedback carefully, and we recommend that advisors empower trainees to take ownership of their projects. In a coaching capacity, advisors can help trainees set development goals and reflect on lessons learned. We encourage ongoing sharing of feedback to identify what is working well and what can be improved.

Trainees and advisors interact many times over the course of the program, often informally, and we encourage trainees to lead these interactions. To help teams and advisors stay on track, we recommend that the organizing committee facilitate structured meetings at key intervals (e.g., launch event, monthly engagement meetings, showcase; Table 2). Events can be hosted in-person or virtually. We recommend that important milestone events be held in-person, as they are more conducive to building connections. In the 2020 iteration of the ITCS program, events shifted online due to the COVID-19 pandemic and continued to be effective.

\section{Support Participants Throughout Their Journey}

To maintain engagement, the organizing committee can remind participants of the features, benefits, framework, and timelines throughout the program. In the ITCS program, in addition to facilitating milestone meetings, the organizing committee provides handbooks summarizing expectations, timelines, roles and responsibilities, example projects, and suggestions on how trainees can leverage their job simulation experience. For example, to demonstrate evidence of knowledge, skills and experience, trainees have included their project in job application packages

Figure 1

Options for Matching Advisors with Trainees

ADVISORS

TRAINEES

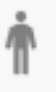

站

$\operatorname{trin}$
袖

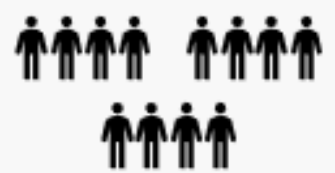

The organizing committee can design the program such that advisors participate as individuals or in a panel, and trainees participate as individuals or in teams. The organizing committee matches advisors and trainees accordingly. 
Table 2

Program Milestones and Objectives

\begin{tabular}{|c|c|c|}
\hline MILESTONE & OBJECTIVE & TIMING \\
\hline $\begin{array}{l}\text { Prepare for } \\
\text { program }\end{array}$ & $\begin{array}{l}\text { Establish the organizing committee, secure program } \\
\text { sponsor(s), and define the program framework, duration } \\
\text { and scale. }\end{array}$ & $\begin{array}{l}6 \text { to } 12 \text { months } \\
\text { prior to program } \\
\text { start }\end{array}$ \\
\hline $\begin{array}{l}\text { Advisor } \\
\text { recruitment and } \\
\text { onboarding session }\end{array}$ & $\begin{array}{l}\text { Organizing committee recruits advisors, and } \\
\text { communicates roles and expectations during an } \\
\text { onboarding session. }\end{array}$ & $\begin{array}{l}3 \text { to } 6 \text { months } \\
\text { prior to program } \\
\text { start }\end{array}$ \\
\hline $\begin{array}{l}\text { Trainee } \\
\text { pre-program } \\
\text { information } \\
\text { session* }\end{array}$ & $\begin{array}{l}\text { Recruit trainees by introducing the advisors and } \\
\text { disciplines, conveying the benefits and structure of the } \\
\text { program, and helping trainees focus their objectives. }\end{array}$ & $\begin{array}{l}1.5 \text { months } \\
\text { prior to program } \\
\text { start }\end{array}$ \\
\hline $\begin{array}{l}\text { Trainee application } \\
\text { deadline and } \\
\text { selection }\end{array}$ & $\begin{array}{l}\text { Organizing committee screens applications, assembles } \\
\text { trainee teams and matches them with advisors. }\end{array}$ & $\begin{array}{l}1 \text { month } \\
\text { prior to program } \\
\text { start }\end{array}$ \\
\hline Launch event* & $\begin{array}{l}\text { Organizing committee communicates program } \\
\text { structure, timeline, and roles and responsibilities to all } \\
\text { participants. Trainee teams and advisors meet for the } \\
\text { first time. }\end{array}$ & Program start \\
\hline $\begin{array}{l}\text { Engagement } \\
\text { meetings* }\end{array}$ & $\begin{array}{l}\text { Meeting 1. Teams introduce their topic, learning } \\
\text { objectives, and project plan. } \\
\text { Meeting 2. Teams present progress and challenges, and } \\
\text { seek advice. } \\
\text { Meeting 3. Teams summarize their findings and } \\
\text { insights, and discuss opportunities for refinement. } \\
\text { At each meeting, advisors provide feedback on project } \\
\text { scope, relevance, progress, information sources, and } \\
\text { quality of the deliverables. }\end{array}$ & $\begin{array}{l}\text { Monthly, throughout } \\
\text { the program }\end{array}$ \\
\hline Showcase event* & $\begin{array}{l}\text { Trainees present project outcomes and key learnings to } \\
\text { peers, advisors, and other invited professionals. A } \\
\text { Question and Answer session is included. }\end{array}$ & $\begin{array}{l}\text { Last day of the } \\
\text { program }\end{array}$ \\
\hline
\end{tabular}

*Networking sessions can be added to events for trainees to engage with advisors and for advisors to scout talent. 
Table 3

Project concepts from the ITCS program

\begin{tabular}{|c|c|}
\hline DISCIPLINE & PROJECT CONCEPT \\
\hline Medical Affairs & $\begin{array}{l}\text { - Physician engagement plan to support launch of drug X } \\
\text { - Evidence generation plan (including clinical trials and real world evidence) to } \\
\text { characterize the use of drug X in areas of unmet medical need } \\
\text { - Summarizing conference highlights and developing a knowledge translation } \\
\text { plan for physicians }\end{array}$ \\
\hline Regulatory Affairs & $\begin{array}{l}\text { - Request for Priority Review of New Drug Submission for drug X } \\
\text { - Regulatory requirements to support approval of software as a medical device } \\
\text { - Options for resubmission of New Drug Submission for drug X that received a } \\
\text { Notice of Deficiency from Health Canada }\end{array}$ \\
\hline $\begin{array}{l}\text { Market Access / } \\
\text { Reimbursement }\end{array}$ & $\begin{array}{l}\text { - Health economic model and budget impact analysis to support submission of } \\
\text { drug X to Canadian Agency for Drugs and Technologies in Health (CADTH) } \\
\text { - Market access strategy for drug X } \\
\text { - Plan to engage patient organizations to support health technology assessment } \\
\text { submissions }\end{array}$ \\
\hline $\begin{array}{l}\text { Business } \\
\text { Development / } \\
\text { Marketing }\end{array}$ & $\begin{array}{l}\text { - Marketing strategy to segment customers and patient groups in preparation for } \\
\text { launch of drug X } \\
\text { - Multi-year sales forecast for drug X } \\
\text { - Key message map and competitive differentiation plan for drug X }\end{array}$ \\
\hline
\end{tabular}

and highlighted their experience in the cover letter and resume. This has resulted in getting noticed by employers, and opportunities for meaningful dialog during interviews and networking (Sealey et al., 2020; Yung et al., 2019). Trainees can also be encouraged to continue their projects beyond the program and publish their work.

The organizing committee can inform trainees and advisors of the intellectual freedom and intellectual property policies of the host institution (as applicable). Advisors should be reminded to avoid conflicts of interest related to their primary employment, and to not share proprietary information. Advisors and trainees can be asked to sign an agreement to confirm acceptance of these policies and terms. Should trainees and advi- sors wish to engage in paid consulting or work-for-hire projects, they are able to do so outside the program.

\section{Leverage Advisors' Expertise Through Value-Added Events and} Programs

Value-added events can be added to (or run in parallel with) the job simulation program. For example, career seminars by industry professionals (e.g., advisors) can orient trainees to project possibilities and alleviate the steep learning curve many trainees experience upon entering the program. Resume workshops can help participants understand how to market themselves - including their job simulation experience - effectively. Workplace visits and job shadowing can raise awareness about the employment environment and a typical day at work. One-on-one mentorship and coaching/feedback systems can support career path discussions and skills development. The organizing committee can facilitate these events by coordinating schedules and venues, and suggesting topics. The ITCS program has incorporated a number of these events.

\section{Provide a Platform for Trainees to Showcase Their Projects and Reflect on Their Learnings}

At the end of the program, a showcase event provides an opportunity for trainees to present their learnings and outcomes to a broader audience of professionals including 
potential employers (Table 2). This opportunity is of significant value for trainees who may have limited experience presenting to non-academic audiences. A networking session following this event can help participants make connections. In the ITCS program, projects are showcased through an abstract/poster book which is posted online.

\section{Evaluating Program Effectiveness}

\section{Evaluate Trainee Experience and Achievement of Development Objectives}

Collecting and acting on feedback is key to delivering an impactful program that continues to be relevant. Trainees can be asked to share feedback on their overall experience, logistics, willingness to recommend the program, and how the program helped them to achieve their development objectives. Consider asking trainees about their awareness of industry jobs, sector-specific knowledge, confidence in applying for positions, and motivation for pursuing an industry career. Pre- and post-program responses can be compared to assess the impact of the program, and key performance indicators can be tracked over time.

In the ITCS program, surveys are linked to key events and submission of deliverables (e.g., final abstract). Through exit surveys, trainees have reported a higher level of confidence in being hired for a job in industry.

\section{Ask Advisors to Provide Feedback on Impact of the Program, and Trainee Development}

\section{Collecting feedback from} advisors will help to continually improve the program so that it serves its mission as a bridge to employment. Advisors can provide feedback on the structure and content of the program, the level of difficulty for trainees, and ways to further support trainees' development. This information can be collected throughout the program and through exit surveys/interviews.

\section{Tracking Employment Outcomes of Program Alumni}

Employment metrics of program alumni can be tracked to assess the impact of the job simulation program and other activities trainees may be engaged in. We recommend following program participants and their employment milestones (e.g., time to employment after graduation, employer, industry sector, and discipline) over time. Methods of tracking graduate alumni have been described by others (Silva et al., 2019). Employment outcome data can be leveraged in promotional materials to recruit sponsorship, advisors, and trainees. As of January 2021, based on publicly available data, the first occupations of ITCS program alumni who completed their degrees/training $(n=106 / 184)$ were in the following sectors: industry (55\%), academic/healthcare $(28 \%)$, non-profit $(2 \%)$, government $(1 \%)$, and unknown (14\%; percentages approximate). Employment success stories of ITCS program alumni were reported recently (Sealey et al., 2020; Yung et al., 2019).

\section{Conclusion}

To compete effectively in the job market, trainees need knowledge, skills, and experience that employers can relate to. These areas can be developed through experiential learning including job simulation. Academic institutions interested in recruiting top students and elevating the societal impact of their alumni, and employers interested in acquiring and developing talent can be motivated partners in these initiatives. Through job simulation programs, trainees can engage with industry professionals and demonstrate their abilities.

Our collective experience designing and running the ITCS program over 5 years has taught us key lessons for talent development of early career trainees through a job simulation program.

- If a program does not exist, start one. Trainees do not need permission to start simulating the work they may seek to be paid for in the future. Teaming up with like-minded peers and motivated mentors can increase the probability of success and lead to a scalable program.

- Identify development objectives and measure progress. Trainees who understand their strengths, development needs and career interests, as well as the market for talent, can focus their effort through experiential learning opportunities. Reflecting on accomplishments and learnings will lead to new development goals a cycle that can continue over the course of a career.

- Mentors are valuable coaches who also benefit from the experience. They help trainees identify career options, uncover blind spots, develop specialized skills, and persevere through the process. In turn, they hone their talent development skills.

We hope this paper serves as a useful resource for trainees, academic institutions and employers to create and engage in job simulation programs for the benefit of all involved. 


\section{Acknowledgements}

We thank the many trainees and professionals who have contributed to the design and delivery of the ITCS program.

\section{Disclosures}

DS is employed in the pharmaceutical industry; his employer was not involved in this project.

\section{References}

Archer-Kuhn, B., \& Rancourt, D. (2019). How universities can really help $\mathrm{PhD}$ grads get jobs | University Affairs. https://www. universityaffairs.ca/opinion/ in-my-opinion/how-universitiescan-really-help-phd-grads-getjobs/

BioTalentCanada. (2020). The Talent Differential The case for work-integrated learning in the bio-economy. https://www. biotalent.ca/wp-content/uploads/ BioTalentCanada_LMI-The-Talent-Differential-09OCT2020-1. pdf

Brandt, P. D., Varvayanis, S., Baas, T., Bolgioni, A. F., Alder, J., Petrie, K. A., Dominguez, I., Brown, A. M., Stayart, C. A., Singh, H., Wart, V., Chow, C. S., Mathur, A., Schreiber, B. M., Fruman, D. A., Bowden, B., Holmquist, C. E., Arneman, D., Hall, J. D., ... Layton, R. L. (2020). Measuring effects of trainee professional development on research productivity: A cross-institutional meta-analysis. BioRxiv. https://doi. org/10.1101/2020.09.28.316422

Council of Canadian Acadmies. (2021). Degrees of Success, Ottawa, Ontario: The expert panel on the labour market transitionof
$\mathrm{PhD}$ graduates. isbn: 978-1926522-85-2 (electronic book), 978-1-926522-84-2 (book)

Craig, R., \& Markowitz, T. (2017).

The Skills Gap Is Actually An Awareness Gap -- And It's Easier To Fix. Forbes. https://www.forbes.com/ sites/ryancraig/2017/03/17/ the-skills-gap-is-actually-anawareness-gap-and-its-easier-tofix/\#1f88f3d63ff4

Division of Student Life, University of Toronto. (2020). Centre for Community Partnerships. https:// studentlife.utoronto.ca/department/centre-for-community-partnerships/

Edge, J., \& Munro, D. (2015). Inside and Outside the Academy. The Conference Board of Canada.

Fuhrmann, C. N., Halme, D. G., O'Sullivan, P. S., \& Lindstaedt, B. (2011). Improving graduate education to support a branching career pipeline: Recommendations based on a survey of doctoral students in the basic biomedical sciences. CBE Life Sciences Education, 10(3), 239-249. https://doi.org/10.1187/ cbe.11-02-0013

Her, S., Jacob, M. D., Wang, S., Xu, S., \& Sealey, D. C. (2018). Non-academic employability of life science PhDs: the importance of training beyond the bench. BioRxiv. https://doi. org/10.1101/485268

Hitchcock, P., Mathur, A., Bennett, J., Cameron, P., Chow, C., Clifford, P., Duvoisin, R., Feig, A., Finneran, K., Klotz, D. M., McGee, R., O’Riordan, M., Pfund, C., Pickett, C., Schwartz, N., Street, N. E., Watkins, E., Wiest, J., \& Engelke, D. (2017). The future of graduate and postdoctoral training in the biosciences. ELife, 6, 1-7. https://doi.
org/10.7554/eLife.32715

Langin, K. (2019). Private sector nears rank of top Ph.D. Employer. Science, 363(6432), 1135. https://doi.org/10.1126/science.363.6432.1135

Lenzi, R. N., Korn, S. J., Wallace, M., Desmond, N. L., \& Labosky, P. A. (2020). The NIH "BEST" programs: Institutional programs, the program evaluation, and early data. FASEB Journal, 34(3), 3570-3582. https://doi. org/10.1096/fj.201902064

Meyers, F. J., Mathur, A., Fuhrmann, C. N., O’Brien, T. C., Wefes, I., Labosky, P. A., Duncan, D. S., August, A., Feig, A., Gould, K. L., Friedlander, M. J., Schaffer, C. B., Van Wart, A., \& Chalkley, R. (2016). The origin and implementation of the Broadening Experiences in Scientific Training programs: An NIH common fund initiative. FASEB Journal, 30(2), 507-514. https://doi.org/10.1096/ fj.15-276139

Mitacs. (2020). Mitacs. https://www. mitacs.ca/en

Porter, S., Mol, L., Locher, J., \& Johnston, M. (2017). UBC PhD Career Outcomes Graduates from 2005-2013. 1-44. http:// outcomes.grad.ubc.ca/docs/ UBC_PhD_Career_Outcomes_ April2017.pdf

Reithmeier, R., O’Leary, L., Zhu, X., Dales, C., Abdulkarim, A., Aquil, A., Brouillard, L., Chang, S., Miller, S., Shi, W., Vu, N., \& Zou, C. (2019). The 10,000 $\mathrm{PhDs}$ project at the University of Toronto: Using employment outcome data to inform graduate education. PLoS ONE, 14(1), 1-12. https://doi.org/10.1371/ journal.pone.0209898

Roach, M., \& Sauermann, H. (2017). The declining interest in an academic career. PLoS 
ONE, 12(9), 1-23. https:// doi.org/10.1371/journal. pone. 0184130

Schnoes, A. M., Caliendo, A., Morand, J., Dillinger, T., NaffzigerHirsch, M., Moses, B., Gibeling, J. C., Yamamoto, K. R., Lindstaedt, B., McGee, R., \& O’Brien, T. C. (2018). Internship Experiences Contribute to Confident Career Decision Making for Doctoral Students in the Life Sciences. CBE Life Sciences Education, 17(1), 1-14. https://doi. org/10.1187/cbe.17-08-0164

School of Graduate Studies, University of Toronto. (2020). Graduate Professional Skills Program Information Session. https:// www.sgs.utoronto.ca/event/graduate-professional-skills-gps-program-information-session/

Sealey, D., Yung, A.,Rinchon,C., Wehrle, C. (2020). Case studies give grad students a chance to tackle industry challenges. University Affairs. https://www.universityaffairs.ca/career-advice/ career-advice-article/case-studies-give-grad-students-a-chanceto-tackle-industry-challenges/

Silva, E. A., Mejía, A. B., \& Watkins, E. S. (2019). Where do our graduates go? A tool kit for tracking career outcomes of biomedical PhD students and postdoctoral scholars. CBE Life Sciences Education, 18(4), 1-6. https://doi.org/10.1187/cbe.1908-0150

Sinche, M., Layton, R. L., Brandt, P. D., O'Connell, A. B., Hall, J. D., Freeman, A. M., Harrell, J. R., Cook, J. G., \& Brennwald, P. J. (2017). An evidence-based evaluation of transferrable skills and job satisfaction for science PhDs. PLoS ONE, 12(9), 1-16. https://doi.org/10.1371/journal. pone. 0185023
Tomasson Goodwin, J., Goh, J., Verkoeyen, S., \& Lithgow, K. (2019). Can students be taught to articulate employability skills? Education and Training, 61(4), 445-460. https://doi.org/10.1108/ ET-08-2018-0186

University of Alberta. (2020). Career Mentoring Program. https:// www.ualberta.ca/career-centre/ programs-services/career-mentoring/index.html

University of Toronto. (2020). Graduate and Life Sciences Education. https://www.glse.utoronto. $\mathrm{ca} /$

Wart, A. Van, O'brien, T. C., Varvayanis, S., Alder, J., Greenier, J., Layton, R. L., Stayart, C. A., Wefes, I., \& Brady, A. E. (2020). Applying experiential learning to career development training for biomedical graduate students and postdocs: Perspectives on program development and design. CBE Life Sciences Education, 19(3), 1-12. https://doi. org/10.1187/cbe.19-12-0270

Yung, A., Rinchon, C., Wehrle, C., Sealey, D. (2019). Getting hired in industry - life science graduate students use case studies to get noticed by employers. OSF Preprints. https://doi. org/10.31219/osf.io/x6fny 